Maurice A. Deane School of Law at Hofstra University Scholarly Commons at Hofstra Law

Hofstra Law Faculty Scholarship

2000

\title{
Understanding Conflict and Human Capacity: The Role of Premises in Mediation Training
}

Robert A. Baruch Bush

Maurice A. Deane School of Law at Hofstra University

Sally G. Pope

Follow this and additional works at: https://scholarlycommons.law.hofstra.edu/faculty_scholarship Part of the Dispute Resolution and Arbitration Commons

\section{Recommended Citation}

Robert A. Baruch Bush and Sally G. Pope, Understanding Conflict and Human Capacity: The Role of Premises in Mediation Training, 38 $41(2000)$

Available at: https://scholarlycommons.law.hofstra.edu/faculty_scholarship/208

This Article is brought to you for free and open access by Scholarly Commons at Hofstra Law. It has been accepted for inclusion in Hofstra Law Faculty Scholarship by an authorized administrator of Scholarly Commons at Hofstra Law. For more information, please contact lawcls@hofstra.edu. 


\section{UNDERSTANDING CONFLICT \\ AND HUMAN CAPACITY \\ The Role of Premises in Mediation Training}

Sally Ganong Pope and Robert A. Baruch Bush

In this article, the authors point out that underlying mediator practices and techniques, there are deeper premises and values that guide and shape practice. The authors argue that mediation training should include articulation and explanation of the premises that underlie the form of practice being taught. They describe the particular premises that underlie the transformative orientation to mediation practice and give examples of how those premises can be conveyed within an overall training design, and how doing so enriches the teaching of skills and techniques themselves.

The field of mediation attracts practitioners from a wide spectrum of professional backgrounds. Every article about mediation in the popular or professional press draws many who self-select themselves as mediators and sign up for mediation training. What is it that motivates people to become mediators? For many, it goes beyond a desire to help people in conflict to resolve problems and to become a "negotiations manager"; the deep appeal arises from a desire to change the way conflict is experienced in personal, social; and public life. Even more fundamentally, the concept of mediation speaks to premises, often unarticulated, about conflict and the capacity of human beings to change, strengthen the self, and respond to each other through the experience of conflict, and it is this optimism, this worldview, that draws practitioners to the field. ${ }^{1}$

Not all would agree. The controversy about facilitative and evaluative mediation, ${ }^{2}$ for example, appears on the surface to be about how to mediate but actually makes clear that mediators disagree about the purpose of mediation, not just the methods to achieve an agreed purpose. Often presented as an argument about techniques, the actual, but not explicit, controversy is about our underlying beliefs and goals as mediators. As commentators survey the mediation terrain and argue about what they see, they are often looking at the view from very different houses. Within individual houses, the foundational values and premises may be shared but may not have been examined and made explicit. Examination of the foundations, the premises, is helpful in understanding the differences in the field and, when introduced into mediation

FAMILY AND CŌNCILIATION COURTS REVIEW, Vol. 38 No. 1, January 2000 41-47 Q 2000 Sage Publications, Inc. 
training, helps mediators understand their goals for intervening in conflict as well as how to do so. This article summarizes the foundations of the transformative perspective, considers the value of introducing premises into training, and describes some ways in which that might be done. ${ }^{3}$

Ask any group of experienced mediators to recall highlights from their practices when something happened that they experienced as significant and valuable, whether or not the parties reached an agreement. The accounts of such moments, the success stories, quickly produces a long list. Mediators readily recall moments when a party "really heard what the other was saying," "showed persistence and commitment," "understood how he had hurt the other," "cleared up misunderstanding," or "realized for the first time what she wanted to happen." In some cases, the moment may have made an agreement possible, or it made agreement irrelevant. Of even more significance is the fact that the event was seen as important and valued by the parties and the mediator even in situations where no agreement was reached.

Research supports what mediators know and value from their own experiences. Parties reported high satisfaction in mediation when they were able to deal with the issues they felt were important, had the opportunity to present their views fully, had a sense of being heard, and were helped to better understand each other. Even when no settlement was reached and even when they "did worse" in mediation than they might have in court, they were satisfied as a result of a process that helped achieve those results. ${ }^{4}$

These achievements, which mediators intuitively value and parties report as most important, are often considered incidental to the work of mediation. They are considered "nice" if they happen on the way to working on the substantive matters, but not something a mediator can or should try to produce. There is inconsistency in this viewpoint. The view of the mediator as a settlement technician carrying a toolbox to fix up a settlement for the parties is inconsistent with the appeal of mediation, what we know are the most valuable results that may be attained, and beliefs about potential for growth in conflict.

\section{THE PREMISES}

Conflict presents opportunity - mediators are taught this belief as a basic principle, often with the Chinese character for conflict that represents both danger and opportunity. But what is the danger and what is the opportunity? A mediator with a transformative orientation believes conflict is a crisis in human relationship and interaction, and it could be, and often is, a starting point for destructive interaction between the persons involved. However, it also presents an opportunity to change the interaction from destructive to 
constructive. A constructive interaction begins when the person in conflict reacts in ways that strengthen the self and increase responsiveness to the other, in spite of the reaction of the other and the host of usual physical, intellectual, and emotional responses to conflict that make this difficult. Thus, the mediator believes that conflict presents opportunities for growth in these two dimensions: self-determination and responsiveness to other.

To see the opportunities presented by conflict, the mediator must have a belief in the capacity of human beings for change. Accepting and trusting that innate capacity for movement toward self-determination and responsiveness to other human beings, like a plant growing toward the sunlight, is an essential premise to doing the work. This underlying trust in the capacity of human beings is essential if the mediator is to work toward the goals of mediation: supporting the parties' movement in both dimensions. The mediator will support full deliberation and informed decision making by the parties about all issues in the mediation, substantive and procedural, including whether there is a settlement that will resolve the issues. Understanding their own goals, the resources available, and the possible choices - and then making decisions about them-all help parties in conflict move from weakness to strength, the shift we call empowerment. At the same time, the mediator supports communication and voluntary and mutual perspective-taking by the parties. The resulting changes in understanding of each other can help parties move from selfabsorption to greater responsiveness to one another, the shift we call recognition.

True change cannot be forced, so the mediator will only support the parties' efforts and help them open doors to consider whether they wish to enter. The mediator is not interested in persuading the parties to go in any particular direction, including one leading to agreement, unless that is what they decide to do. The mediator is interested in helping the parties to talk and explore what they want to do, individually and together, in a positive and constructive interaction. The experience of the process has the potential to increase capacity in the individual to make decisions and communicate more effectively in other settings. It also has the potential to shift the experience of conflict itself from destructive to constructive regardless of the outcome of the mediation.

Given the premise of the human potential for shifts in both dimensionsweakness to strength and self-absorption to responsiveness-mediators are relieved of the need to create the result in mediation. The result can be left to the efforts of the parties. We can trust that they want to resolve the conflict in the best way possible on the basis of self-determination and consideration for the other. Acceptance of this premise, and reliance on it, guide the choices mediators make in working with the parties. Mediators will be responsive to the parties in their interventions in the conflict in ways that will support party 
choices and the opportunity to take the other into account in the choices. Choices may extend to all aspects of the mediation process, such as setting ground rules, 'as well as the actual decision making about the issues in conflict. Since parties are trusted to be able to handle the situation as well as to make decisions, there is no need for the mediator to direct the flow of the conversation, to cut off discussion of certain subjects, to "soften" the parties' words by reframing, to generate options, or to persuade the parties to select an option or encourage them to reach settlement at all.

Unlike directive mediators who are oriented to solving concrete problems and who use persuasion to influence the parties to reach an agreement that the mediator believes is right, fair, and realistic, the mediator with a transformative orientation focuses on the interaction in the moment and the opportunities it offers to work in both dimensions, empowerment and recognition. It is at this level of actual mediator interventions that the differences in orientation and approach become glaringly apparent. Our society places much value on experts and professionals. Many mediators have been, and still are, professionals in other settings and find it difficult to give up the expert, advicegiving role and learn how to turn the decision making over to the parties while being helpful and supportive. Without an understanding of the premises and some resonance with them, mediators will not relinquish the directive methods learned in social and professional settings as well as in many mediation trainings.

\section{INTRODUCING PREMISES INTO TRAINING}

The premises of the transformative framework do resonate with many trainees, particularly when those premises, are the basis for the trainees' attraction to mediation. For them, the presentation of premises simply articulates something they already know explicitly or implicitly, and the challenge for them will be to act consistently as mediators in accordance with their values. For others with whom these premises resonate less, the challenge will be to consider exactly what they do believe and whether they. want to try to act on the basis of values they do not think they fully embrace.

In transformative training, the premises underlying the transformative orientation are presented, and a number of exercises are used to enable the trainees to connect with and consider the value of empowerment and recognition. For experienced mediators, asking them to describe their recollections of significant and valuable moments in mediations (the success stories described above) puts them in touch with what they value in mediation. In debriefing this discussion, the trainer will point out how the descriptions of what was 
valuable track the two dimensions of growth, as this is invariably the case. When the mediators are also asked what in the mediation process helped bring about the significant results, the trainees then start to think and talk about the ways in which a mediator may support the parties in reaching these important results.

Connecting trainees to their own experiences in other ways also enhances their understanding of empowerment and recognition and their value. To allow trainees themselves to experience the value of empowerment, an exercise called Getting Clear provides the opportunity for trainees to talk to partners about situations in their personal or professional lives in which they feel unsure, uncertain, or unclear about what they should do. The listening partners are asked to help the speakers gain greater clarity or insight for themselves, without being directive. Even with just 15 minutes of talking about the situation, many of the speakers report gaining clarity, developing new ways of thinking about their situations, seeing new choices and new ideas to deal with them, and even resolving the matters for themselves. Because becoming clear about a conflict situation is one aspect of empowerment, the trainees directly and personally experience the value of empowerment with this exercise, either through their own experience or by hearing others talk about the experience in positive terms.

Presentation, exercises, and stories are also used to help trainees connect to the second dimension of growth-that of responsiveness to the other, or recognition. This dimension is often more difficult to experience in the training setting than that provided by the experience of the Getting Clear exercise. Certainly, some of the responses to the success stories illustrate recognition at work in actual cases. Use of "difficult person" and "shifts happen" exercises also illustrates the value of recognition to trainees from their own experience. Talking about a difficult person in one's own life to a partner who is asked to try to help the speaker see the difficult person in a new light often does just that, but it runs the risk of many participants trying to help the speaker solve the problem. Small-group discussion of past events in their lives when they experienced or observed real shifts in their own thinking about other people often produces powerful stories about those experiences and helps the trainees to understand the value of this dimension of conflict transformation.

Once the premises are understood and the common training experiences establish the premises and goals of mediation as empowerment and recognition, the trainers and trainees have a common language and rationale to apply to the further experiences of observing and practicing mediation in role plays. The opportunities for empowerment and recognition happen moment to moment in mediation and matter more than any particular outcome. Therefore, emphasis is placed on understanding the flow of opportunities and look- 
ing at critical points for intervention. Vignettes of critical points are used to analyze and construct responses. Role plays of longer duration are generally interrupted frequently by the trainers to focus on the actual responses to opportunities as they arise and to avoid continuing demonstrations of a directive line of questions or responses. Again, the common language and understanding provided before the practice of mediation provides the framework for the discussion and feedback.

Teaching mediation from the transformative orientation to beginning mediators with significant time devoted to the nature of conflict and the potential for growth in conflict unleashes excitement about the opportunities inherent in mediation-and in conflict. Our experience of working with both beginning and advanced mediators has made clear that many trainees have difficulty of letting go of the outcome-orientation and trusting the parties to make the best decisions for themselves. Even trainees quite committed to the values and promise of mediation find it hard to truly let go in the moment-tomoment development of a mediation. It is hard, when hearing about the real problems faced by the people in front of you, not to start problem solving for them rather than simply assisting them as they go through their own problem-solving process. We have few models in our society for this sort of professional or helping person. We are accustomed to the "expert" advicegiver and problem-solver. Many mediators-in-training have been in that role in other professions, such as lawyer, therapist, or teacher. Becoming a mediator for them may be even more difficult because they must avoid applying other expert professional skills in the mediation setting. But even for those without such expert training, our culture, with its activist, can-do approach to problems, creates the model of the helper as adviser and solver.

A person may leave mediation training saying, "I want to protect and defend weaker parties" or "I want to be sure the parties find the right solution." Those trainees have understood the premises underlying the training and have decided they do not want to take a transformative orientation to practice. By making the premises explicit, we are assisting our trainees to better understand mediation and the role.of the mediator, and to examine their own views and values for consistency with what is being asked of them. If some choose not to become mediators or choose to move into a different mediator house with others who also see the mediator as an.arbiter of fairness and particular results consonant with societal or mediator values, then a service has been provided to the trainees and to the field of mediation.

For those who are inspired to.continue within a transformative orientation to practice, a training course that has articulated premises has assisted the trainees in understanding their choice and will help them to deliberately and successfully adopt the supportive, nondirective approach required for media- 
tion. Trainees leave training with a rationale and with an understanding of their goals and premises, not just with a toolbox of techniques. However, one word of caution for mediators who choose to experiment, even if with some skepticism, with the transformative orientation, although this is offered with some skepticism. They may be surprised. Some mediators have found themselves transformed by the experience. The responsiveness and changes in the parties convince the mediator to trust them and the premises of the transformative framework.

\section{NOTES}

1. In the development of mediation training for the REDRESS Mediation Program of the U.S. Postal Service, working with Joe Folger and Dorothy Della Noce we developed an approach to mediation training from the transformative arientation that attempts to make clear the premises underlying the mediation training--premises about the goals of mediation itself and the role of the mediator. This article draws on that experience of developing a training incorporating premises and delivering it to trainers and mediators across the United States.

2. See Kimberlee K. Kovach and Lela P. Love, Mapping Mediation: The Risks of Riskin's Grid, 3 HȦRV. NEG. L. REv. 71 (1998), and Leonard L. Riskin, Understanding Mediators' Orientations, Strategies, and Techniques: A Grid for the Perplexed, 1 Harv. Neg. L. Rev. 7 (1996).

3. The summary here is necessarily abbreviated. For a fuller explanation, see Bush and Folger, THE Promise OF MEDIATION (1994), and Transformative Mediation and Third-Party Intervention: Ten Hallmarks of a Transformative Approach to Practice, 13 MEDIATION QUARTERLY 263 (1996).

4. Robert A. B. Bush, What Do We Need a Mediator For? Mediation's "Value-Added".for Negotiators, 12 OHIo STATE J. OF DisPUTE Resol. 1 (1996).

Sally Ganong Pope, M.Ed., J.D., is a practicing mediator and trainer in New York City. She is cofounder of the Institute for the Study of Conflict Transformation, Inc., at HofstraLaw School, and an adjunct professor at Cardozo School of Law. She is the immediate past president of the Academy of Family Members.

Robert A. Baruch Bush, B.A., J.D., is the Rains Distinguised Professor of ADR Law at Hofstra University School of Law, and a cofounder of the Institute for the Study of Conflict Transformation, Inc. He is author of many articles on mediation and ADR, and coauthor (with Joseph P. Folger) of The Promise of Mediation: Responding to Conflict Through Empowerment and Recognition-(1994). 